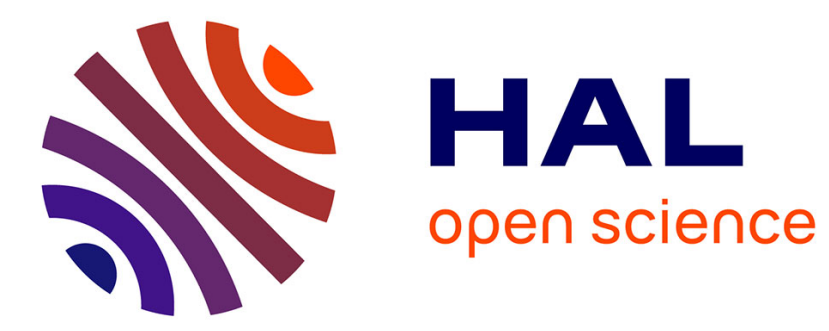

\title{
Design, Analysis and Validation of a Simple Dynamic Model of a Submerged Membrane Bioreactor
}

Guilherme Araujo Pimentel, Alain Vande Wouwer, Jerome Harmand, Alain

Rapaport

\section{- To cite this version:}

Guilherme Araujo Pimentel, Alain Vande Wouwer, Jerome Harmand, Alain Rapaport. Design, Analysis and Validation of a Simple Dynamic Model of a Submerged Membrane Bioreactor. Water Research, 2015, 70, pp.97-108. 10.1016/j.watres.2014.11.043 . hal-01087630

\section{HAL Id: hal-01087630 \\ https://hal.inria.fr/hal-01087630}

Submitted on 27 May 2020

HAL is a multi-disciplinary open access archive for the deposit and dissemination of scientific research documents, whether they are published or not. The documents may come from teaching and research institutions in France or abroad, or from public or private research centers.
L'archive ouverte pluridisciplinaire HAL, est destinée au dépôt et à la diffusion de documents scientifiques de niveau recherche, publiés ou non, émanant des établissements d'enseignement et de recherche français ou étrangers, des laboratoires publics ou privés. 


\section{Accepted Manuscript}

Design, Analysis and Validation of a Simple Dynamic Model of a Submerged Membrane Bioreactor

Guilherme A. Pimentel, Alain Vande Wouwer, Jérôme Harmand, Alain Rapaport

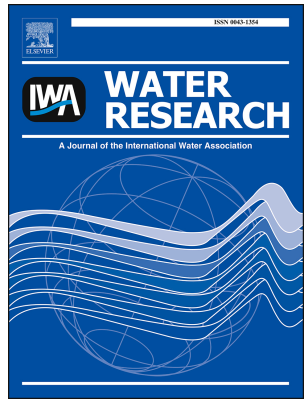

PII:

S0043-1354(14)00822-7

DOI:

10.1016/j.watres.2014.11.043

Reference: WR 11026

To appear in: Water Research

Received Date: 5 August 2014

Revised Date: 21 October 2014

Accepted Date: 24 November 2014

Please cite this article as: Pimentel, G.A., Vande Wouwer, A., Harmand, J., Rapaport, A., Design, Analysis and Validation of a Simple Dynamic Model of a Submerged Membrane Bioreactor, Water Research (2015), doi: 10.1016/j.watres.2014.11.043.

This is a PDF file of an unedited manuscript that has been accepted for publication. As a service to our customers we are providing this early version of the manuscript. The manuscript will undergo copyediting, typesetting, and review of the resulting proof before it is published in its final form. Please note that during the production process errors may be discovered which could affect the content, and all legal disclaimers that apply to the journal pertain. 
-For control purposes, a simple dynamic model of a membrane bioreactor is proposed;

-The process behavior is analyzed, showing the existence of slow-fast dynamics;

-A parameter identification procedure exploiting time scale separation is presented. 


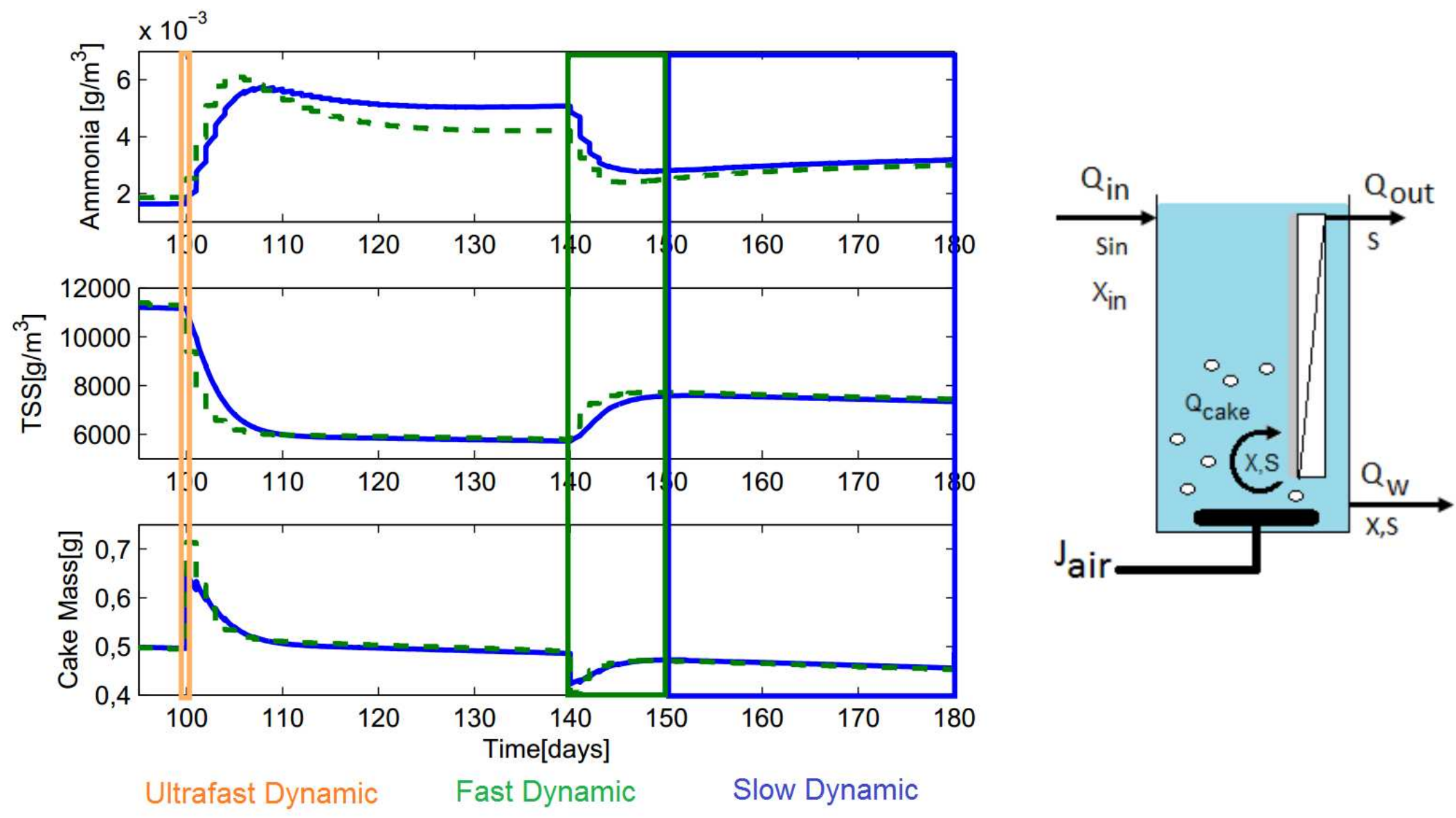




\title{
Design, Analysis and Validation of a Simple Dynamic Model of a Submerged Membrane Bioreactor
}

\author{
Guilherme A. Pimentel ${ }^{\mathrm{a}, \mathrm{b}, \mathrm{d}, *}$, Alain Vande Wouwer ${ }^{\mathrm{a}}$, Jérôme Harmand ${ }^{\mathrm{b}, \mathrm{c}}$, \\ Alain Rapaport ${ }^{\mathrm{b}, \mathrm{d}}$ \\ ${ }^{a}$ University of Mons - Automatic Control Laboratory - Biosys, Boulevard Dolez 31, 7000 \\ Mons, Belgium \\ ${ }^{b}$ Equipe Projet INRA-INRIA MODEMIC, Route des Lucioles 06902 Sophia-Antipolis, \\ France \\ ${ }^{c}$ INRA, UR050, Laboratoire de Biotechnologie de l'Environnement, Av. des Etangs, \\ F-11100 Narbonne, France \\ ${ }^{d}$ UMR INRA-SupAgro MISTEA, 2 Place Viala 34060 Montpeller, France
}

\begin{abstract}
In this study, a simple dynamic model of a submerged membrane bioreactor (sMBR) is proposed, which would be suitable for process control. In order to validate the proposed model structure, informative data sets are generated using a detailed simulator built in a well-established environment, namely GPS-X. The model properties are studied, including equilibrium points, stability, and slow/fast dynamics (three different time scales). The existence of slow-fast dynamics is central to the development of a dedicated parameter estimation procedure. Finally, a nonlinear model predictive control is designed to illustrate the potential of the developed model within a model-based control structure. The problem of water treatment in a recirculating aquaculture system is considered as an application example.
\end{abstract}

Keywords: Mathematical modeling; Singular perturbation; Parameter estimation; Model-based control; Recirculating aquaculture system;

* Corresponding author. This work is part of the $\mathrm{PhD}$ work of the first author, to be defended at UMons (Belgium) and Univ. Montpellier II (France).

Email addresses: guilherme.araujopimentel@umons.ac.be (Guilherme A. Pimentel), alain.vandewouwer@umons.ac.be (Alain Vande Wouwer), jerome.harmand@supagro.inra.fr (Jérôme Harmand), rapaport@supagro.inra.fr (Alain Rapaport) 


\section{Introduction}

Submerged membrane bioreactors (sMBR) are increasingly used for wastewater treatment with a relative success (Judd \& Judd, 2011). In its simplest configuration, a sMBR combines the functions of an activated sludge aerobic system, secondary clarifier, and tertiary filter in a single tank (Atasi et al., 2006). The advantages are the footprint reduction, high effluent quality and the decoupling of the hydraulic retention time (HRT) and solid retention time (SRT). Due to filter pore size, particles however start to attach on membrane surface, forming a deposition of solid matter, responsible for fouling. Membrane fouling decreases membrane permeability, increasing operating costs.

One of the greatest challenges for process optimization is the development of an integrated model (comprising biological phenomena and filtration mechanism). In general, sMBR models are stand-alone filtration models including aeration (Ferrero et al., 2011), cake formation (Li \& Wang, 2006), filtration and fouling (Robles et al., 2013a,b; Charfi et al., 2012), physical and bioprocess description (Bella et al., 2008; Mannina et al., 2011). Regarding the biological phenomena, the activated sludge models (ASM) are widely accepted (Henze et al., 1987). Studies have shown that ASM can be directly implemented or modified taking the fouling interference on activated sludge biology (SMP/EPS) into account (Fenu et al., 2010; Naessens et al., 2012). ASM1, ASM3 and ASM2d have been extensively used to predict the effluent quality related to soluble matter (Sarioglu et al., 2009; Lee et al., 2002; Jiang et al., 2009; Zarragoitia-González et al., 2008). A critical review of sMBR models has been done by Fenu et al. (2010) and Naessens et al. (2012) presenting biokinetics, filtration, hydrodynamics and integrated models intended for process description and understanding. These models cover a wide range of phenomena, from empirical to first principles, and have been used mainly for process cognition development (Naessens et al., 2012). In order to compare and evaluate control strategies, an sMBR benchmark for wastewater treatment has been developed by Maere et al. (2011). 
However, those models include many parameters which can be delicate to estimate from experimental data and they are in general too complex for control purposes. As a general rule, it is always necessary to make a trade-off between model complexity and dynamic predictive capability. For control purposes, a model should not be more detailed than required by a specific control task (Kokotović et al., 1986). In this context, there are only a few proposals of sMBR models based on empirical approaches (Khan et al., 2009), artificial neural network models (Choi et al., 2012) or black box model to estimate filtration performance (Dalmau et al., 2013).

The main objective of this study is to develop a simplified sMBR model, and to validate it by comparison with a well established simulator, e.g., GPS-X (Hydromantis, 2012). In this connection, the detailed simulator is used as an emulation of a real plant to generate realistic data. The advantage of a simulator is of course that data can be produced easily and without the operational constraints of a real-life plant. Hence, more informative data sets (i.e. data sets exploring the plant behavior in a wider operating range, and containing sufficient information on the plant dynamics) can be used to test and validate the simplified model. To this end, a dedicated parameter estimation strategy is proposed and applied to fit the reduced model to these data sets. This identification study is the opportunity to emphasize the need for an appropriate design of experiments to ensure a sufficient level of information. An interesting feature of the system dynamics is the possibility to consider different time scales (fast and slow dynamics), which are evidenced in this study using singular perturbation theory. This approach reveals conditions on the model parameters to obtain reduced models at three different time scales. The time scale separation can be used advantageously in system identification, as subsets of parameters can be estimated on different time intervals, and the identification problem can in this way be divided into simpler subproblems. Once the simplified model has been identified, it can be used in model-based control schemes and a "proof of concept" is showed at the end of this study, where nonlinear model predictive control (NMPC) is used as an appealing approach. It is important to stress 
that model based control could be very delicate if based on complex physical models, due to their large number of variables and parameters, which makes identification, estimation and control difficult or even impossible. In contrast, the simplified model has a much reduced set of variables and parameters and is very convenient for NMPC or other nonlinear model based control approaches.

As a particular application example, a recirculating aquaculture system (RAS) is considered, which can be defined as a process that reuses water and has less than $10 \%$ of total volume replaced per day (Piedrahita, 2003; Hutchinson et al., 2004). This recirculation however causes accumulation of ammonia, nitrate and organic matter that should be removed before reentering the system. Nitrogen removal for RAS normally includes some filtering technologies such as rotating biological contactors, trickling filters, bead filters and fluidized sand biofilters (Crab et al., 2007). The application of sMBR in this context is still a relatively new prospect.

This study is organized as follows. The next section presents the case study related to a recirculating aquaculture process and describes the modeling assumptions (Section 2). Section 3 derives the proposed model structure for the sMBR. The model is analyzed considering short-term and long-term evolution in Section 4, and an analysis with regard to the equilibrium points is presented in Section 5. The parameter estimation procedure is discussed in Section 6 and a nonlinear model predictive control is developed in Section 7. Finally, Section 8 draws some conclusions and perspectives.

\section{Process Description}

A sustainable fish production can be achieved by treating and recirculating the effluent water of the fish tanks, see Figure 1a. This is only achievable if efficient nitrification, denitrification and organic removal can be setup. Normally, fish are susceptible to high concentrations of ammonia, which result from fish feces and excretion, but tolerate higher nitrate concentrations. This is for instance the case for tilapia and trout, as reported in Eding et al. (2006). Based 
on these classes of fish this work provides a simplified model of the ammonia removal process in sMBR.

Figure 1b shows the sketch of the nitrification compartment with membrane bioreactor. This illustration is a simplified representation of the two tanks inside the dashed square in Figure 1a. The advantage of lumping both reactors is to model only the dynamics that are the most important for process control, without considering all the internal variables and parameters of the process. This leads to a simplified input-output black-box model with a "biologically inspired" structure, but with much less variables and parameters.

The considered process has a constant trans-membrane pressure and the effluent flow $Q_{\text {out }}\left[\mathrm{m}^{3} / d\right]$ decreases due to deposition of the particles on the membrane surface. To avoid this phenomenon, sMBR are usually equipped with air diffusers in the bottom part. A diffuser produces an air crossflow, $J_{\text {air }}\left[m^{3} / m^{2} d\right]$, that is injected to detach the particle agglomerate from the membrane surface. Figure 2 describes the fouling evolution in time, which can be split in two parts. Initially $\left(t_{0}\right)$, the permeate pump is off and there is no material attached to the membrane. As time goes on $\left(t^{+}\right)$, the permeate pump is active and solid particles are conveyed by the flow towards the membrane surface, resulting in membrane fouling (formation of a "cake"). In the longer term $\left(t^{++}\right)$, the effluent flow decreases with time, due to the cake build-up on the membrane surface (considering a process with constant trans-membrane pressure and air crossflow).

\section{Model Development}

The particle deposition creates a resistance to the flow through the membrane. On inspection of the literature, several descriptions of the total fouling resistance can be found (Busch et al., 2007; E.Remigi, 2008; Lee et al., 2002; Sarioglu et al., 2012). In this work the total fouling resistance $\left(R_{\text {total }}\left[\mathrm{m}^{-1}\right]\right)$ is represented by equation (1). Based on experiments reported by Lee et al. (2002) and Khan et al. (2009), the cake resistance, $R_{\text {cake }}\left[m^{-1}\right]$, can be consid- 
ered as the main responsible for fouling resistance. $R_{m}\left[\mathrm{~m}^{-1}\right]$ is the intrinsic resistance and $\delta_{R}$ is used to represent total resistance disturbance, resulting from pore-blocking, biofilm, concentration polarization and scaling resistances.

$$
R_{\text {total }}=R_{m}+R_{\text {cake }}+\delta_{R}
$$

The effluent rate is given by $Q_{\text {out }}=\Delta P / \eta R_{\text {total }}$, where $\Delta P[P a]$ is the trans-membrane pressure and $\eta[P a . s]$ is the water apparent viscosity. The cake resistance is ruled by $R_{\text {cake }}=\rho \frac{m+m 0}{A}$, where $\rho\left[m \cdot g^{-1}\right]$ is the specific cake resistance, $m_{0}[g]$ is the initial cake mass, $A$ is the area of the membrane surface and $m[g]$ is the current cake mass. The latter can be described by equation (2).

$$
\frac{d m}{d t}=Q_{c a k e} X-J_{a i r} \mu_{a i r}(m) m, \text { with } \mu_{a i r}(m)=\beta \frac{m}{K_{a i r}+m}
$$

The right hand side of equation (2) has two terms. The first term represents the attachment of total suspended solids on the membrane surface which depends on the effluent rate $Q_{\text {cake }}\left[\mathrm{m}^{3} / d\right]$ and its concentration $X\left[\mathrm{~g} / \mathrm{m}^{3}\right]$. The flow $Q_{\text {cake }}=\psi Q_{\text {out }}$ is responsible for the fixation of suspended particle matter onto the cake. It is assumed that the concentration of substrate that passes through the membrane is equal to the concentration of the solids that attach onto it when $\psi=1$. The time scale is represented in Figure 2 by $t^{+}$, showing that the particles that are in suspension near the membrane walls are rapidly forced against the filter. The second term of equation (2) represents the cake detachment proportional to air crossflow. The parameter $\beta\left[m^{-1}\right]$ is linked to the resistance of the cake to detachment. This latter mechanism is of course influenced in the first place by $J_{a i r}$, but also by the mass of the cake. With an increasing attached mass, detachment becomes more likely and this is represented by a 'Monod law' like equation, i.e., a monotone law with saturation (saturation occurrence being adjusted by the half-saturation coefficient $K_{\text {air }}$ ). This model structure guarantees that the cake mass will never reach negative values, that indeed is physically impossible. This time scale dynamic compared to the other dynamics of the process can be understood as an instantaneous 
behavior, see more explanation in Section 4 .

Having proposed a membrane filtration model, the biological activity is described using a simple chemostat reactor (Smith \& Waltman, 1995), involving one biomass growing on a limiting substrate, equation (3). It is important to highlight that this simple biological model structure can be easily extended to more than one biological reaction, see for instance Dochain \& Vanrolleghem (2001). However, adding details and complexity will make model calibration more delicate and reduce model suitability to control purposes.

$$
\left\{\begin{array}{l}
\frac{d S}{d t}=-\frac{1}{Y} \mu(S) X+\frac{Q_{i n}}{V}\left(S_{\text {in }}-S\right) \\
\frac{d X}{d t}=\left(\mu(S)-\frac{Q_{w}}{V}\right) X+\frac{Q_{\text {in }}}{V} X_{\text {in }}-\frac{Q_{\text {cake }}}{V} X+\frac{J_{\text {air }}}{V} \mu_{\text {air }}(m) m
\end{array}\right.
$$

Equation (3a) represents the consumption of the substrate by the free biomass, ruled by a Monod law $\mu(S)=\mu_{S, \max } \frac{S}{K_{S}+S}$, and the transportation of incoming and outgoing substrate through the tank. Note that the substrate is not affected by the membrane, knowing that only solid matter are retained.

Equation (3b) shows that there is an interaction between the suspended solid and cake build-up. The first part of the equation represents the growth of the free biomass that consumes the substrate. Material transportation involves the cake attachment by $\frac{-Q_{c a k e} X}{V}$ and detachment and the instantaneous "conversion" in suspended solids by the air crossflow $+\frac{J_{a i r}}{V} \mu_{a i r}(m) m$. The free particle matter is transformed in cake and vice-versa depending on the process input values. The waste flow is represented by $Q_{w}$ and the influent is defined as $Q_{i n}=Q_{w}+Q_{\text {cake }}$. The biological time scale is governed by the consumption rate of substrate and consequently the growth of biomass. This rate is represented by a Monod law equation $(\mu(S))$ and is normally measured in days.

In a continuous process a long-term evolution of the cake is observed, which can be modeled by

$$
\frac{d \beta}{d t}=\gamma \beta
$$


The parameter $\beta\left[\mathrm{m}^{-1}\right]$ represents the ease (or difficulty) of detaching the cake from the membrane using an air crossflow. In a process with constant transmembrane pressure, the permeate flow decreases with time. Hence $\beta$ increases, $\gamma\left[d^{-1}\right]$ is positive, meaning that the efficiency of $J_{\text {air }}$ increases as a consequence of the loss of the drag force of the membrane to the particle deposition. In the other sense, if the process has constant permeate flow, the capacity of $J_{a i r}$ to detach the cake decreases, $\beta$ decreases, thus $\gamma$ has a negative value. One can also relate this phenomenon to the cake compression coefficient proposed by Li \& Wang (2006). It is important to highlight that this phenomenon has a longterm behavior, which is observed on a time scale depending on the process cycles: Permeate cycle ( $Q_{\text {cake }}$ is considered as a positive and constant value), relaxation cycle (where the air crossflow is maintained constant and the permeate flow is zero, resulting in a zero trans-membrane pressure) and backwash cycle $\left(Q_{\text {cake }}\right.$ flow is reversed to force the particles detachment). Normally this evolution is measured in weeks or months (Merlo et al., 2000).

Regrouping the previous equations, the integrated model is represented by (5), where $\beta, S, X$ and $m$ are always positive and bounded (properties that are linked to the biological and physical phenomena that rule the process).

$$
\left\{\begin{aligned}
\frac{d \beta}{d t}= & \gamma \beta \\
\frac{d S}{d t}= & -\frac{1}{Y} \mu(S) X+\frac{Q_{i n}}{V}\left(S_{i n}-S\right) \\
\frac{d X}{d t}= & \left(\mu(S)-\frac{Q_{w}}{V}\right) X+\frac{Q_{i n}}{V} X_{i n}-\frac{Q_{\text {cake }}}{V} X+\frac{J_{\text {air }}}{V} \mu_{\text {air }}(m) m \\
\frac{d m}{d t}= & Q_{\text {cake }} X-J_{\text {air }} \mu_{\text {air }}(m) m \\
& \text { with } \mu(S)=\mu_{S, \max } \frac{S}{K_{S}+S}, \quad \mu_{\text {air }}(m)=\beta \frac{m}{K_{\text {air }}+m}
\end{aligned}\right.
$$

This dynamic model is generic and could be used in various applications. In this study, a particular example is considered, so as to demonstrate that the model structure is appropriate. In this context, assuming there is no oxygen limitation, the state variables $S$ and $X$ denote the concentrations of ammonia 
and autotrophic bacteria, respectively. Note that the model could easily be extended to processes with other species and substrates.

\section{Fast and Slow Dynamics}

The simplified model involves three different time scales: cake attachment and detachment, biology and cake long-term evolution.

The simultaneous occurrence of fast and slow phenomena contribute to complex dynamics, stiffness of the model and computational effort for simulation.

To simplify the model analysis, the singular perturbation approach is used. The presence of a small parameter in the description of the dynamic model that can (regular perturbation) or cannot (singular perturbation) be approximated by putting the small parameter to zero, reveals the possibility of model reduction in dimension or in order (Saksena et al., 1984; Kokotović et al., 1986). Detecting the different time scales results in reduced models, where the slowest phenomenon is the dominant dynamics. This can be understood as an inner and outer process loop. The fast dynamics, named also boundary layer, represents the deviation from the predicted slow behavior. This approach is considered in more details in the framework of singular perturbations.

\subsection{Singular Perturbations}

The mathematical tool used to deal with the different time scales is Tikhonov's theorem which allows reducing the complexity of the system through suitable approximations (Khalil, 2002). A slow-fast system is in singular perturbation form when it can be expressed in suitable coordinates, so as to distinguish two subsystems with a small positive parameter $\epsilon$.

$$
\left\{\begin{array}{l}
\dot{x}=f(t, x, z, \epsilon) \\
\epsilon \dot{z}=g(t, x, z, \epsilon)
\end{array}\right.
$$

The function $f$ and $g$ are continuously differentiable in their arguments for $(t, x, z, \epsilon) \in\left[0, t_{1}\right] \times D_{x} \times D_{z} \times\left[0, \epsilon_{0}\right]$, where $D_{x} \subset R^{n}$ and $D_{z} \subset R^{m}$ are open connected sets. Considering $\epsilon=0$ in (6), the dimension of the state equation 
reduces from $n+m$ to $n$ because the differential equation degenerates into the algebraic equation.

$$
0=g(t, x, z, 0)
$$

We assume that (7) admits $k \geq 1$ isolated real roots

$$
z=h_{i}(t, x), i=1,2, \ldots, k
$$

defined by $(t, x) \in\left[0, t_{1}\right] \times D_{x}$. This assumption ensures that a well-defined $n$-dimensional reduced model will correspond to each root of (7). To obtain the $i^{\text {th }}$ reduced model, equation (8) has to be substituted into (6), at $\epsilon=0$, to obtain

$$
\dot{x}=f\left(t, x, h_{i}(t, x), 0\right)
$$

It will be clear from the context which root of (7) are used. This model is sometimes called a quasi-steady-state model, because $z$, whose velocity $\dot{z}=g / \epsilon$ can be large when $\epsilon$ is small and $g \neq 0$, may rapidly converge to a root of (7), which is the equilibrium of (6). Equation (9) is called the slow dynamics of the model (Sari, 2005).

\subsection{Three-time-scale Singular Perturbation}

In the previous subsection, fast and slow theory is recalled considering two time scales. In the sMBR model, three time scales can be identified: the cake attachment is considered as the ultrafast time scale, the free biomass growth and substrate consumption as the fast time scale and the evolution of the cake as the slow time scale resulting in the following generic representation:

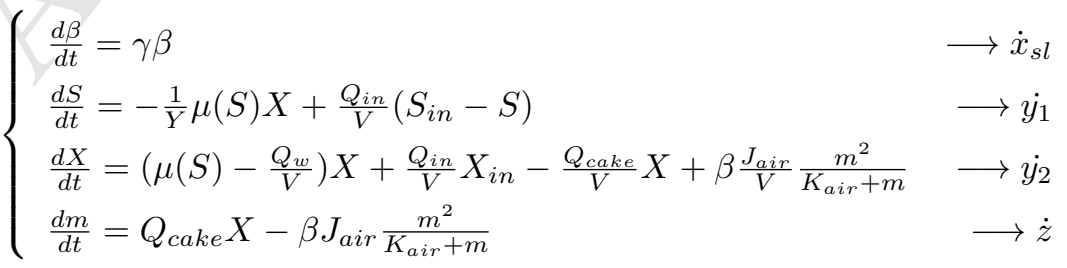


$\epsilon_{1} \frac{d y_{1}}{d \tau_{2}}=-\frac{1}{Y} \mu\left(y_{1}\right) y_{2}+\frac{Q_{i n}}{V}\left(S_{i n}-y_{1}\right)$

$$
\begin{array}{lr}
\epsilon_{1} \frac{d y_{2}}{d \tau_{2}}=\left(\mu\left(y_{1}\right)-\frac{Q_{w}}{V}\right) y_{2}+\frac{Q_{i n}}{V} X_{\text {in }}-\frac{Q_{\text {cake }}}{V} y_{2}+x_{s l} \frac{J_{\text {air }} \frac{z^{2}}{V}}{K_{\text {air }}+z} & \text { (Fast) } \\
\epsilon_{2} \epsilon_{1} \frac{d z}{d \tau_{2}}=h\left(x_{s l}, y, z\right)=Q_{\text {cake }} y_{2}-x_{s l} J_{\text {air }} \frac{z^{2}}{K_{\text {air }}+z} & \text { (Ultrafast) }
\end{array}
$$$$
\frac{d x_{s l}}{d \tau_{1}}=\epsilon_{1} x_{s l}
$$$$
\epsilon_{1} \frac{d y_{1}}{d \tau_{1}}=g_{1}\left(x_{s l}, y_{1}, h_{2}\right)=\left[-\frac{1}{Y} \mu\left(y_{1}\right) y_{2}+\frac{Q_{i n}}{V}\left(S_{i n}-y_{1}\right)\right] \epsilon_{2}
$$$$
\epsilon_{1} \frac{d y_{2}}{d \tau_{1}}=g_{2}\left(x_{s l}, y_{2}, h_{2}\right)=
$$$$
\left[\left(\mu\left(y_{1}\right)-\frac{Q_{w}}{V}\right) y_{2}+\frac{Q_{i n}}{V} X_{i n}-\frac{Q_{c a k e}}{V} y_{2}+x_{s l} \frac{J_{a i r}}{V} \frac{z^{2}}{K_{a i r}+z}\right] \epsilon_{2} \quad \text { (Fast) }
$$$$
\epsilon_{1} \frac{d z}{d \tau_{1}}=h\left(x_{s l}, y, z\right)=Q_{c a k e} y_{2}-x_{s l} J_{a i r} \frac{z^{2}}{K_{a i r}+z}
$$$$
0=g_{1}\left(x_{s l}, y_{1}, h_{2}\left(x, y_{1}\right)\right) \longrightarrow y_{1}=\frac{Q_{w} K_{s}}{\mu_{\max }-Q_{w}}
$$$$
0=g_{2}\left(x_{s l}, y_{2}, h_{2}\left(x, y_{2}\right)\right) \longrightarrow y_{2}=\frac{Q_{i n} Y\left(S_{i n}\left(V \mu_{\max }-Q_{w}\right)-Q_{w} K_{s}\right)}{Q_{w}\left(V \mu_{\max }-Q_{w}\right)}
$$$$
0=h\left(x_{s l}, y, z\right) \longrightarrow z=\frac{\frac{Q_{\text {cake }} y_{2}}{x J_{a i r}}+\sqrt{\left(\frac{Q_{\text {cake }} y_{2}}{x_{s l} J_{a i r}}\right)^{2}+\frac{4 K_{\text {air }} Q_{\text {cake }} y_{2}}{x_{s l} J_{\text {air }}}}}{2}
$$

Second: The stretched time scale $\tau_{2}=\frac{\tau_{1}}{\epsilon_{2}}=\frac{t}{\epsilon_{1} \epsilon_{2}}$ and $x_{s l}$ is constant. 


$$
0=h\left(x_{s l}, y, z\right) \longrightarrow z=\frac{\frac{Q_{c a k e} y_{2}}{x J_{a i r}}+\sqrt{\left(\frac{Q_{c a k e} y_{2}}{x_{s l} J_{a i r}}\right)^{2}+\frac{4 K_{a i r} Q_{c a k e} y_{2}}{x_{s l} J_{a i r}}}}{2}
$$

\section{Model Analysis}

In this section, we compute the equilibrium points, analyze their stability based on a linearization (Jacobian matrix).

\subsection{Asymptotic Analysis}

The filtration process is an unstable process by nature, since solid matter continuously accumulate in an irreversible manner (see the dynamic of $\beta$ in equation (5)), but it is possible to analyze it on a short time span $t$, where the process could be considered stable. Analyzing the process in this period, the long-term evolution of the cake is neglected (i.e. it is considered constant). Based on a fast and slow dynamics study, the coupling of the system is simplified and thus when the equilibrium points of $S$ and $X$ are computed, $m$ is considered constant, and reversely, when $m$ is computed, $S$ and $X$ are considered constant. This helps in determining the biomass and cake equilibrium points that are strongly coupled.

$$
\begin{gathered}
\bar{S}=\frac{Q_{i n} X_{i n}-Q_{w} \bar{X}-Q_{i n} S_{i n} Y}{Q_{i n}} \\
\bar{X}=\frac{Q_{i n} X_{i n}}{Q_{w}-\mu(S) V} \\
\bar{m}=\frac{\frac{Q_{\text {cake }} \bar{X}}{\beta J_{a i r}}+\sqrt{\left(\frac{Q_{\text {cake }} \bar{X}}{\beta J_{a i r}}\right)^{2}+\frac{4 K_{a i r} Q_{c a k e} \bar{X}}{\beta J_{a i r}}}}{2}
\end{gathered}
$$

\subsection{Study of the Linearized Dynamics - Short Term}

The dynamic equations (5) are linearized about the equilibrium point (15),(16), (17) and the long-term dynamic $\beta$ is considered constant. This is only possible if 
this analysis is done for a short period of time. Assuming that Jacobian matrix is given by

$$
\left[\begin{array}{ccc}
-\frac{1}{Y} \mu^{\prime}(S) X-\frac{Q_{i n}}{V} & -\frac{1}{Y} \frac{Q_{w}}{V} & 0 \\
\mu^{\prime}(S) X & -\frac{Q_{c a k e}}{V} & +\beta \frac{J_{a i r}}{V}\left(\frac{2 m\left(K_{\text {air }}+m\right)-m^{2}}{\left(K_{\text {air }}+m\right)^{2}}\right) \\
0 & Q_{\text {cake }} & -\beta J_{\text {air }}\left(\frac{2 m\left(K_{\text {air }}+m\right)-m^{2}}{\left(K_{\text {air }}+m\right)^{2}}\right)
\end{array}\right]
$$

considering $\mu(S)=\frac{\mu_{\max } S}{K_{S}+S}, \mu^{\prime}(S)=\frac{\mu_{S, \max }}{K_{S}+S}-\frac{\mu_{S, \max } S}{\left(K_{S}+S\right)^{2}}$.

A necessary and sufficient condition for a third-order Jacobian to be stable is to have a negative trace and determinant. Hence, to stabilize the cake dynamics, $J_{\text {air }}$ should be such that $J_{\text {air }}>\left(2 m\left(K_{\text {air }}+m\right)-m^{2}\right) /\left(\beta\left(K_{\text {air }}+m\right)^{2}\right)$ and to prevent the undesired equilibrium (washout) $0<Q_{w}<\left(S_{i n} \mu_{\max }\right) /\left(K_{s}+S_{i n}\right)$. This strategy is empirically used by the sMBR operators that change permeate flux (i.e. changing directly cake mass $(m)$ attachment (see equation (2))) and air crossflow set-points to reach an equilibrium point resulting in a constant cake mass. The Jacobian matrix computation is only valid on a short term, when the long-term cake evolution phenomenon can be neglected.

\section{Model Simulation and Identification}

In this section, we exploit the well-established GPS-X simulator (Hydromantis, 2012), so as to generate realistic simulation data, which can be used as a database for the estimation of the parameters of our simplified model. Our objective is to show that the simplified model is able to reproduce the behavior of a more detailed process representation, implemented in a recognized software environment.

The considered process, which is taken as an application example, has a membrane permeate flow of $18,75 \mathrm{~L} /\left(\mathrm{m}^{2} h\right)$, resulting in an influent flow of $0.16284 \mathrm{~m}^{3} / d$. The nitrification process is composed of two aerobic tanks, the first tank has a volume of $0.09 \mathrm{~m}^{3}$ and the second, which includes the membrane, has a volume of $0.045 \mathrm{~m}^{3}$. The sludge retention time of the plant is 25 days, and the hydraulic retention time 0.5 days. The total area of the membrane 
is $0.35 \mathrm{~m}^{2}$. The total suspended solids concentration in the membrane compartment ranges from 5 to $15 \mathrm{~g} / \mathrm{L}$. The influent characteristics are extracted from Viadero Jr. et al. (2005) with total suspended solids of $10.9 \mathrm{~g} / \mathrm{m}^{3}$, BOD of $2.4 \mathrm{~g} / \mathrm{m}^{3}$ and total ammonia nitrogen of $1.5 \mathrm{~g} / \mathrm{m}^{3}$.

The simulator makes use of specific GPS-X modules (and not of our proposed model at this stage) with ASM1 as biological model and the TMP computation for the membrane. Standard conditions of $20^{\circ} \mathrm{C}$, at see level with barometric pressure of one atm are set. To illustrate the previous discussion, the process trajectory is computed over a period of 150 days: the first 100 days with an air crossflow of $2.86 \mathrm{~m} / \mathrm{d}$ and the next 50 days with a reduced flow of $1.43 \mathrm{~m} / \mathrm{d}$. Figure 3 clearly shows the existence of at least three time scales, ultrafast, fast and slow, thus confirming our observation in the previous section. The ultrafast behavior of the cake mass is evident when air flow is changed. A fast time scale is then observed which corresponds to the transient of the substrate and free biomass. Finally, a slow evolution of the cake is apparent (the evolution of the cake has been reported by Merlo et al. (2000) with a fouling rate constant of $\left.0.001 d^{-1}\right)$.

In Figure 4, a phase plane plot of three GPS-X simulations with different initial conditions are presented. Note that the system rapidly converges to the equilibrium point, which confirms our analysis of a fast evolution of the suspended solids to the cake.

The proposed model has been solved using ode45 (a variable-step explicit Runge-Kutta method) and ode15s (an implicit solver for stiff ODEs based on numerical differentiation formulas) as implemented in Matlab, using a Intel Celeron $2.20 \mathrm{GHz}$ processor, and the simulation times are respectively 211.65 seconds and 3.08 seconds, demonstrating the process stiffness.

In order to fit the response of the simplified model to the experimental data collected from the GPS-X simulator, the weighted least-squares cost function

$$
J(\theta)=\sum_{i=1}^{n_{t}}\left(\left(\xi_{\text {sim }}(i)-\xi_{G P S-X}(i)\right)\right)^{T} \Omega^{-1}\left(\left(\xi_{\text {sim }}(i)-\xi_{G P S-X}(i)\right)\right)
$$


is minimized, where $\xi_{G P S-X}=\left[\begin{array}{lll}S & X & m\end{array}\right], \xi_{\text {sim }}=\left[\begin{array}{lll}S_{\text {sim }} & X_{\text {sim }} & m_{\text {sim }}\end{array}\right], \theta=$ $\left[\beta_{0}, K_{a i r}, Y, \mu_{S, \max }, \gamma\right], n_{t}$ is the number of measurements and $\Omega$ is defined as a scaling matrix that is selected as a diagonal matrix of the square of the maximum values corresponding to each state. The optimization is performed in this study using a Nelder Mead algorithm as implemented in fminsearch in Matlab.

A lower bound on the covariance matrix $\hat{P}$ of the parameter estimates is obtained by the inverse of the Fisher Information Matrix (FIM):

$$
\hat{P}=F^{-1}(\hat{\theta})
$$

The FIM is computed by:

$$
F(\hat{\theta})=\sum_{i=1}^{n_{t}}\left[\frac{\partial Y_{m}}{\partial \theta}\right]_{\left(t_{i}, \hat{\theta}\right)}^{T} \Omega^{-1}\left[\frac{\partial Y_{m}}{\partial \theta}\right]
$$

The square root $\sigma_{j}$ of the $j^{\text {th }}$ diagonal element of $\hat{P}$ is an estimate of the standard deviation of $\hat{\theta}$, which is used to obtain the parameters confidence intervals of $2.56 \sigma$ corresponding to a probability of $99 \%$.

Based on the fast and slow dynamics analysis, parameter identification can be organized in three steps corresponding to the three time scales. Indeed, a direct identification of all the parameters at once is delicate and leads to the occurrence of several local minima. A divide and conquer approach is therefore used, where subsets of parameters are estimated first, and the full set of parameters is then re-estimated starting from the previous estimates, which are then much closer to the optimum and severely decrease the computation efforts.

Figure 5 shows simulation results corresponding to step-changes in the membrane aeration at day 100 and 140 with values of $1.43 m / d$ and $2 m / d$, respectively. The ultrafast (orange), fast (green) and slow (blue) time windows are shown. The parameters related to ultrafast dynamics $\beta_{0}$ which is considered constant and $K_{\text {air }}$ are first estimated using the data collected on a period of 0.02 days, while all the other parameters are fixed (to some initial values that can be randomly chosen in the parameter space using the latin hypercube strategy - see later). Then, the biological parameters that are linked to the fast 
dynamics $\left(Y\right.$ and $\left.\mu_{S, \max }\right)$ are estimated from data collected on a period of six days (all the other parameters being fixed) and finally, the remaining slow dynamics parameter $(\gamma)$ is estimated from data on a period of 33 days (again all the other parameters being fixed to their last estimated values). The three successive parameter identification steps are followed by an identification of all parameters at once, starting from the current parameter estimates, and using the full data set. The resulting vector of parameters $\theta$ is the starting point for a new sequence of ultrafast, fast, slow partial identification and identification of all parameters. This process can be iterated as necessary, but for this application it is observed that after two iterations the minimization algorithm converges to one single point. The results are shown in Table 2.

Following the identification procedure, it is important to test the predictive capability of the model with a set of data that has not been used in the identification procedure, i.e., the so-called model cross-validation. This step is important to check if the parameters that have been inferred from the experimental data, indeed translate the process behavior, and not only some specific and restricted operating conditions. In this study, the initial conditions and air crossflow are changed, e.g., to $2.29 \mathrm{~m}^{3} / d, 2.86 \mathrm{~m}^{3} / d, 2 \mathrm{~m}^{3} / d$ and $1.43 \mathrm{~m}^{3} / d$, at days 100,120, 160 and 180, respectively. Figure 6 shows the satisfactory cross-validation results.

The correlation matrix of the estimated parameters is presented in Table 3. It is apparent that $\beta_{0}$ is correlated with $Y$ and $\mu_{S, \text { max }}$, since the value of $\beta_{0}$ affects biomass and in turn the substrate concentration. The pair of parameters $Y$ and $\mu_{S, \max }$ are strongly correlated, which is often the case in bioprocess identification. Note that $K_{a i r}$ is the short-term detachment factor and is correlated with $\gamma$ that rules the behavior of the long-term detachment, proving again the three time scales behaviors.

Accurate correlation coefficients $\left(R^{2}\right)$ of $0.98,0.94$ and 0.93 are obtained for the substrate, free suspended solids and cake build-up outputs. Figure 7 represents the L1-norm of the normalized parametric sensitivities (Muñoz Tamayo et al., 
2009). The matrix is computed by $\sum_{i=1}^{n t}\left|\frac{\hat{\theta}_{j}}{y_{m}\left(t_{i}, \hat{\theta}\right)}\left[\frac{\partial y_{m_{k}}}{\partial \hat{\theta}}\right]_{\left(t_{i}, \hat{\theta}\right)}\right|$ and shows the interaction between the identified parameters and states. Note that the brown color denotes that the parameter is more susceptible to the state variation, meaning that this parameter is strongly linked to this state and the opposite for parameters with the dark blue color.

In addition, a multi-start strategy using the Latin Hypercube Sampling (LHS) is used (McKay et al., 1979). The LHS method is a form of stratified sampling, which allows to achieve a reasonably accurate random distribution, while reducing the computational costs associated with Monte Carlo techniques. The parameter bounds defining the exploration space are fixed at plus $50 \%$ and minus $50 \%$ of the nominal values found after identification in Table 2. Parameter estimation is repeated 80 times using LHS. The minimum costs for all trials are summarized in Table 4, showing that the minimum found has a relatively large region of attraction.

One can observe that, some parameters presented in Table 2 do not totally converge with the standard parameters of the ASM1 model (Henze et al., 1987). This can be explained, due to the simple fact that simplified model is used to fit a complex data behaviour. Nonetheless, GPS-X uses detailed models, such as the full ASM1 (Henze et al., 1987) for the biological compartment, and this study demonstrates that under standard operating conditions, a simple model can capture the main dynamics.

\section{7. sMBR Process Control}

The main motivation behind the development of a simple dynamic model is the potential of applying advanced model-based control. Especially, simple models involve a reduced set of state variables, which can be measured by online probes or estimated on-line using observers (or software sensors). State feedback can therefore be developed efficiently. Large models, on the contrary, often lead to measurement and observability problems that cannot so easily be alleviated. 
The purpose of this paper is mostly to present and validate such a simple model, and not to enter in details in the problematic of process control. However, we show by an example that our proposed model is indeed appropriate for modelbased control. One of the most straightforward control approaches, in wide use in industrial process, is Nonlinear Model Predictive Control (NMPC). The advantage of this control technique is its ability to handle model nonlinearity and various types of constraints on the actuators and state variables. In this application the control strategy has three main tasks: (i) maintain cake build-up inside a certain region; (ii) minimize the ammonia effluent concentration; (iii) maximize the effluent. It is important to highlight that these tasks can only be fulfilled based on a model describing biology and filtration, but with a simple structure, so as to reduce the computational effort.

\subsection{Nonlinear Model Predictive Control}

NMPC uses a model to predict the trajectory of the system on a prediction horizon, and computes an optimal control sequence on a control horizon (Allgöwer et al., 2004). The first important element is therefore a nonlinear model in the form:

$$
\dot{x}=f(x(t), u(t)), \quad x(0)=x_{0}
$$

together with constrains in the form $u(t) \in \mathbf{U}, \forall t \geq 0, x(t) \in \mathbf{X}, \forall t \geq 0$ where $x(t) \in \mathbb{R}^{n}$ and $u(t) \in \mathbb{R}^{m}$ are the vector of states and inputs, respectively. The sets $\mathbf{U}$ and $\mathbf{X}$ are compact and can be represented by $\mathbf{U}:=$ $u \in \mathbb{R}^{m}\left|u_{\min } \leq u \leq u_{\max }, \quad \mathbf{X}:=x \in \mathbb{R}^{n}\right| x_{\min } \leq x \leq x_{\max }$ with the constant vector $u_{\min }, u_{\max }$ and $x_{\min }, x_{\max }$.

The NMPC control moves are usually given by the solution of a finite horizon open-loop optimal control problem, which is solved at every sampling instant. 
In generic notation, the NMPC problem can be expressed as:

$$
\begin{gathered}
\min _{\phi_{u}(\cdot)} J_{N M P C}\left(x(t), \phi_{u}(\cdot)\right) \\
\text { s.t. } \dot{\phi}_{x}(\tau)=f\left(\phi_{x}(\tau), \phi_{u}(\tau)\right), \phi_{x}(t)=x(t), \\
\phi_{u}(\tau)=\phi_{u}\left(t+T_{c}\right), \forall \tau \in\left[t+T_{c}, t+T_{p}\right],
\end{gathered}
$$

with the cost function

$$
J_{N M P C}\left(x(t), \phi_{u}(\cdot)\right):=\int_{t}^{t+T_{p}} F\left(\phi_{x}(\tau), \phi_{u}(\tau)\right) d \tau
$$

where $\phi_{u}(\tau) \in \mathbf{U}, \forall \tau \in\left[t, t+T_{c}\right], \phi_{x}(\tau) \in \mathbf{X}, \forall \tau \in\left[t, t+T_{p}\right], T_{p}$ and $T_{c}$ are the prediction and control horizon with $T_{c} \leq T_{p} \cdot \phi_{x}(\cdot)$ denotes the new value of the state $x(\cdot)$ computed by the closed loop equation $\dot{\phi}_{x}$ using the new input value $\phi_{u}$ found by the optimization problem for each instant over the moving finite horizon $T_{c}$.

The cost function, equation (23), is chosen based on the process desired performance. Often the first choice for the cost function is the quadratic function. Positive weighting matrices $\left(\Omega_{1}\right.$ and $\left.\Omega_{2}\right)$ can also be included in the cost function.

$$
F(x, u)=\left(x-x_{r e f}\right)^{T} \Omega_{1}\left(x-x_{r e f}\right)+\left(u-u_{r e f}\right)^{T} \Omega_{2}\left(u-u_{r e f}\right) .
$$

where $x_{r e f}$ and $u_{r e f}$ are the desired reference of a state and input, respectively.

\subsection{Application to sMBR Model}

NMPC, equations (22), are applied to the model equation (5) with the parameter identified in Section 6. The cost function is defined as $F(x, u)=$ $(S)^{2}+\left(1 / Q_{\text {cake }}\right)^{2}$ meaning that ammonia concentration minimization and permeate flow maximization are desired. The following constraints are added: (i) $0 \leq m \leq 1.0[g]$ to avoid reaching the maximum membrane pressure;(ii) $0 \leq Q_{\text {cake }} \leq 4.3\left[\mathrm{~m}^{3} / \mathrm{d}\right]$ for the physical range of the permeate pump. The 
methodology is applied using the Matlab code developed by Grüne \& Pannek (2011).

The results presented in Figure 8 are obtained assuming that all the state variables are measured. NMPC uses a sampling time of 0.1 day, a prediction horizon $T_{p}=10$ days and a control interval of $T_{c}=0.1$ day (so we consider a very simple scenario with only one control move on the control horizon). On the left plot of Figure 8 are represented the ammonia concentration, total particle matter and cake mass. Note that the cake mass is maintained around $1.0[\mathrm{~g}]$ because the input ( $Q_{\text {cake }}$ on the right of the Figure) oscillates to keep the desired response using the detachment propriety of $J_{\text {air }}$, that is constant in this case.

This short application demonstrates that our dynamic model can be used as an effective predictor in a NMPC scheme and that NMPC could probably be applied with success to sMBR processes. Of course, more work would be required to fully explore this option, also with real data. This is currently the subject of further investigations.

\section{Conclusion and Perspectives}

The main contributions of this study are: (i) the development of a simplified dynamic model of a submerged membrane bioreactor, and its validation in the framework of a particular application example, using simulation data generated with the well-established GPS-X environment; (ii) the study of the equilibrium points of the system (stability analysis) which aims at giving a clue to sMBR process operator about the values of air crossflow and permeate flow to maintain a good process efficiency, (theses values are nowadays set by operators on an empirical basis); (iii) the investigation of the fast/slow dynamics of the process (using singular perturbation theory) based on the simplified model, that captures the three main process time scales under conditions of slow evolution of the maximal specific speed of detachment (parameter $\gamma$ ) and large volume of the reactor (parameter V). These time scales correspond to short-term phenomena linked to cake formation, defined as ultrafast dynamics, and mid- and 
long-term phenomena linked to biology and fouling, defined as fast and slow dynamics, respectively;(iv) the proposal of an identification procedure, that could easily be applied to a real process, taking account of the time scale separation; and finally (v) a short "proof of concept" showing that the dynamic model can be the basis for the design of nonlinear control laws, using either analytical techniques to derive globally stabilizing feedback law or numerical techniques, such as model-based predictive control for optimizing the production of treated water (maximizing $Q_{\text {out }}$ ) and at the same time reducing energy consumption (minimizing $J_{\text {air }}$ ).

\section{Acknowlegment}

The first two authors acknowledge the support of the Walloon Region and the Wagralim Pole, in the framework of the Nutrivert Project. This paper presents research results of the Belgian Network DYSCO (Dynamical Systems, Control, and Optimization), funded by the Interuniversity Attraction Poles Programme, initiated by the Belgian State, Science Policy Office. The scientific responsibility lies with its authors. The authors are grateful to UMONS (Belgium) and INRA (MIA Department, France) for the co-funding of the first author.

\section{References}

Allgöwer, F., Findeisen, R., \& Nagy, Z. K. (2004). Nonlinear model predictive control: from theory to application. Journal of the Chinese Institute of Chemical Engineers, 35, 299 - 315.

Atasi, K., Crawford, G., Hudkins, J. M., Livingston, D., Reardon, R., \& Schmidt, H. (2006). Membrane systems for wastewater treatment. WEFPress.

Bella, G. D., Mannina, G., \& Viviani, G. (2008). An integrated model for physical-biological wastewater organic removal in a submerged membrane 
bioreactor: Model development and parameter estimation. Journal of Membrane Science, 322, 1-12.

Busch, J., Cruse, A., \& Marquart, W. (2007). Modeling submerged hollow-fiber membrane filtration for wastewater treatment. Journal of Membrane Science, 288, $94-111$.

Charfi, A., Amar, N. B., \& Harmand, J. (2012). Analysis of fouling mechanisms in anaerobic membrane bioreactors. Water Research, 46, $2637-2650$.

Choi, Y.-J., Oh, H., Lee, S., Nam, S.-H., \& Hwang, T.-M. (2012). Investigation of the filtration characteristics of pilot-scale hollow fiber submerged MF system using cake formation model and artificial neural networks model. Desalination, 297, 20-29.

Crab, R., Avnimelech, Y., Defoirdt, T., Bossier, P., \& Verstraete, W. (2007). Nitrogen removal techniques in aquaculture for a sustainable production. Aquaculture, 270, 1-14.

Dalmau, M., Rodriguez-Roda, I., Ayesa, E., Odriozola, J., Sancho, L., \& Comas, J. (2013). Development of a decision tree for the integrated operation of nutrient removal MBRs based on simulation studies and expert knowledge. Chemical Engineering Journal, 217, 174-184.

Dochain, D., \& Vanrolleghem, P. A. (2001). Dynamical moddeling and estimation in wastewater treatment processes. IWA Publishing.

Eding, E., Kamstra, A., Verreth, J., Huisman, E., \& Klapwijk, A. (2006). Design and operation of nitrifying trickling filters in recirculating aquaculture: A review. Aquacultural Engineering, 34(3), 234 - 260.

E.Remigi (2008). Summer school on modelling MBR processes: MBR modelling - hands-on. Technical Report www.mbr-network.eu.

Fenu, A., Guglielmi, G., Jimenez, J., Sprandio, M., Saroj, D., Lesjean, B., Brepols, C., Thoeye, C., \& Nopens, I. (2010). Activated sludge model (ASM) 
based modelling of membrane bioreactor (MBR) processes: A critical review with special regard to mbr specificities. Water Research, 44, $4272-4294$.

Ferrero, G., Moncús, H., Buttuglieri, G., Gabarron, S., Comas, J., \& RodríguezRoda, I. (2011). Development of a control algorithm for air-scour reduction in membrane bioreactors for wastewater treatment. Journal of Chemical Technology and Biotechnology, 86 (6), $784-789$.

Grüne, L., \& Pannek, J. (2011). Nonlinear Model Predictive Control: Theory and Algorithms. Springer.

Henze, M., Jr, C. L. G., Gujer, W., Marais, G., \& Matsuo, T. (1987). A general model for single-sludge wastewater treatment system. Water Research, 21, $505-515$.

Hutchinson, W., Jeffrey, M., OSullivan, D. D., Casement, D., \& Clarke, S. (2004). Recirculating Aquaculture Systems: Minimum Standards for Design, Construction and Management.. Kent Town, S. Aust. : Inland Aquaculture Association of South Australia, 2004.

Hydromantis (2012). GPS-X, version 6.2.0. Software.

Jiang, T., Sin, G., Spanjers, H., Nopens, I., Kennedy, M. D., van der Meer, W., Futselaar, H., Amy, G., \& Vanrolleghem, P. A. (2009). Comparison of the modeling approach between membrane bioreactor and conventional activated sludge process. Water Environment Research, 81, 432 - 440.

Judd, S., \& Judd, C. (2011). The MBR book, principles and applications of membrane bioreactors in water and wastwater treatment. (2nd ed.). Elsevier.

Khalil, H. K. (2002). Nonlinear System. (3rd ed.). Prentice Hall.

Khan, S. J., Visvanathan, C., \& Jegatheesan, V. (2009). Prediction of membrane fouling in mbr systems using empirically estimated specific cake resistance. Bioresource Technology, 100, $6133-6136$. 
Kokotović, P., Khalil, H. K., \& O'Reilly, J. (1986). Singular Pertubation Methods in Control:Analysis and Design. Academic Press INC.(London)LTD.

Lee, Y., Cho, J., Seo, Y., Lee, J. W., \& Ahn, K.-H. (2002). Modeling of submerged membrane bioreactor process for wastewater treatment. Desalination, $146,451-457$.

Li, X.-y., \& Wang, X.-m. (2006). Modelling of membrane fouling in a submerged membrane bioreactor. Journal of Membrane Science, 278, 151 - 161.

Maere, T., Moerenhout, S., Judd, S., \& Nopens, I. (2011). BSM-MBR: A benchmark simulation model to compare control and operation strategies for membrane bioreactors. Water Research, 45 (6), $2181-2190$.

Mannina, G., Di Bella, G., \& G., V. (2011). An integrated model for biological and physical process simulation in membrane bioreactor (MBRs). Journal of Membrane Science, 376, 56-69.

McKay, M., Conover, W., \& Beckman, R. (1979). A comparison of three methods for selecting values of input variables in the analysis of output from a computer code. Technometrics, 221, 239 - 245.

Merlo, R. P., Adham, S., Gagliardo, P., Trussell, R. S., Trussell, R., \& Watson, M. (Eds.) (2000). Application of membrane bioreactor (MBR) technology for water reclamation volume 27. Proceedings of the Water Environment Federation, WEFTEC 2000: Session 11 through Session 20 Water Environment Federation.

Naessens, W., Maere, T., \& Nopens, I. (2012). Critical review of membrane bioreactor models - part 1: Biokinetic and filtration models. Bioresource Technology, 122, $95-106$.

Piedrahita, R. H. (2003). Reducing the potential environmental impact of tank aquaculture effluents through intensification and recirculation. Aquaculture, 226, 35-44. 
Robles, A., Ruano, M., Ribes, J., Seco, A., \& Ferrer, J. (2013a). A filtration model applied to submerged anaerobic MBRs (SAnMBRs). Journal of Membrane Science, 444, $139-147$.

Robles, A., Ruano, M., Ribes, J., Seco, A., \& Ferrer, J. (2013b). Mathematical modelling of filtration in submerged anaerobic MBRs (SAnMBRs): Longterm validation. Jounal of Membrane Science, 446, 303 - 309.

Saksena, V., O'Reilly, J., \& Kokotović, P. V. (1984). Singular perturbation and time scale methods in control theory: Survey 1976 - 1983. Automatica, 20, $273-293$.

Sari, T. (2005). Contrôle non linéaire et application. Éditeurs des sciences et des arts - Hermman.

Sarioglu, M., Insel, G., Artan, N., \& Orhon, D. (2009). Model evaluation of similtaneous nitrification and denitrification in membrane bioreactor operated without an anoxic reactor. Journal of Membrane Science, 337, 17-27.

Sarioglu, M., Insel, G., \& Orhon, D. (2012). Dynamic in-series resistance modeling and analysis of a submerged membrane bioreactor using a noval filtration mode. Desalination, 285, $285-294$.

Smith, H. L., \& Waltman, P. (1995). The theory of the chemostat. Cambridge University press.

Muñoz Tamayo, R., Laroche, B., Leclerc, M., \& Walter, E. (2009). Ideas:a parameter identification toolbox with symbolic analysis of uncertainty and its application to biological modelling. In 15th Symposium on System Identification.

Viadero Jr., R. C., Cunningham, J. H., Semmens, K. J., \& Tierney, A. E. (2005). Effluent and production impacts of flow-through aquaculture operations in west virginia. Aquacultural Engineering, 33, 258 - 270. 
Zarragoitia-González, A., Schetrite, S., Alliet, M., Jáuregui-Haza, U., \& Albasi, C. (2008). Modeling of submerged membrane bioreactor: Conceptual study about link between activated sludge biokinetics, aeration and fouling process. Journal of Membrane Science, 325, 612 - 624. 
Table 1: Symbols and Notations

\begin{tabular}{cl}
\hline Symbol & Meaning \\
\hline$Y$ & yield coefficient of the substrate consumption $[-]$ \\
$\mu$ & Monod's Law $[1 / d]$ \\
$\mu_{S, \text { max }}$ & maximum growth rate $[1 / d]$ \\
$K_{s}$ & half saturation of substrate $\left[g / \mathrm{m}^{3}\right]$ \\
$X$ & solid matter concentration $\left[\mathrm{g} / \mathrm{m}^{3}\right]$ \\
$Q_{i n}$ & inflow $\left[\mathrm{m}^{3} / \mathrm{d}\right]$ \\
$V$ & tank volume $\left[\mathrm{m}^{3}\right]$ \\
$S_{\text {in }}$ & input substrate concentration $\left[\mathrm{g} / \mathrm{m}^{3}\right]$ \\
$S$ & substrate concentration $\left[\mathrm{g} / \mathrm{m}^{3}\right]$ \\
$Q_{w}$ & waste flux $\left[\mathrm{m}^{3} / d\right]$ \\
$\beta$ & resistance of detachable cake by air crossflow $\left[\mathrm{m}^{-1}\right]$ \\
$J_{\text {air }}$ & air crossflow $\left[\mathrm{m}^{3} / \mathrm{m}^{2} d\right]$ \\
$m$ & mass cake state $[\mathrm{g}]$ \\
$K_{\text {air }}$ & half saturation of airflow $[\mathrm{g}]$ \\
$Q_{\text {cake }}$ & permeate flux $\left(Q_{\text {cake }}=\psi Q_{\text {out }}\right)\left[\mathrm{m}^{3} / d\right]$ \\
\hline
\end{tabular}


Table 2: Parameters with their standard deviation.

\begin{tabular}{cccc}
\hline & $\beta_{0}$ & $K_{\text {air }}$ & $Y$ \\
\hline Ultrafast [0.02 Days] & $(48198.348 \pm 0.175)$ & $(47.733 \pm 0.0002)$ & fixed value \\
Fast [6 Days] & fixed value & fixed value & $(0.897 \pm 0.0424)$ \\
Slow [20 Days] & fixed value & fixed value & fixed value \\
All Parameters & $(55310.548 \pm 0.534)$ & $(45.965 \pm 1.12 e-6)$ & $(0.898 \pm 0.0173)$ \\
\hline & $\mu_{S, \max }$ & $\gamma$ & $\min (J(\theta))$ \\
\hline Ultrafast [0.02 Days] & fixed value & fixed value & 53.55 \\
Fast [6 Days] & $(2 \pm 0.094708)$ & fixed value & 0.8592 \\
Slow [20 Days] & fixed value & $(0.0010081 \pm 0.80756)$ & 6.42 \\
All Parameters & $(2.2654 \pm 0.04371)$ & $(0.0014025 \pm 0.53516)$ & 22.79 \\
\hline
\end{tabular}


Table 3: Correlation matrix of the parameters

\begin{tabular}{cccccc}
\hline & $\beta_{0}$ & $K_{\text {air }}$ & $Y$ & $\mu_{S, \max }$ & $\gamma$ \\
\hline$\beta_{0}$ & 1 & -0.52018 & 0.74435 & 0.74407 & -0.99999 \\
$K_{\text {air }}$ & & 1 & -0.52101 & -0.52084 & 0.52322 \\
$Y$ & & & 1 & 1 & -0.74489 \\
$\mu_{S, \max }$ & & & 1 & -0.74489 \\
$\gamma$ & & & & & 1 \\
\hline
\end{tabular}


Table 4: Minimized Cost Function values with standard deviation. First and second iterations of the full procedure

\begin{tabular}{ccc}
\hline & $\min (J(\theta))_{1}$ & $\min (J(\theta))_{2}$ \\
\hline Ultrafast [0.02 Days] & $(77.49 \pm 145.3)$ & $(52.63 \pm 2.35)$ \\
Fast [6 Days] & $(0.8595 \pm 0.0014)$ & $(0.8592 \pm 0.0013)$ \\
Slow [20 Days] & $(6.58 \pm 2.16)$ & $(6.50 \pm 0.36)$ \\
All Parameters & $(22.86 \pm 1.42)$ & $(22.79 \pm 0.39)$ \\
\hline
\end{tabular}




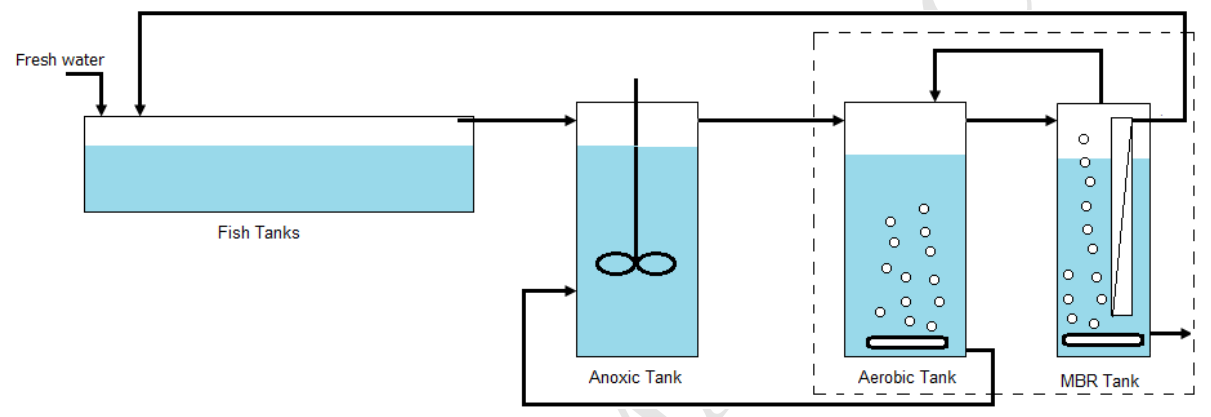

(a) Recirculating aquaculture system fitted with an sMBR.

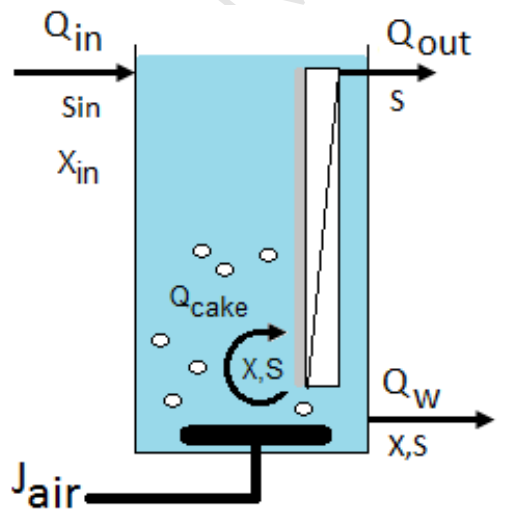

(b) sMBR process sketch

Figure 1: sMBR process structure. 


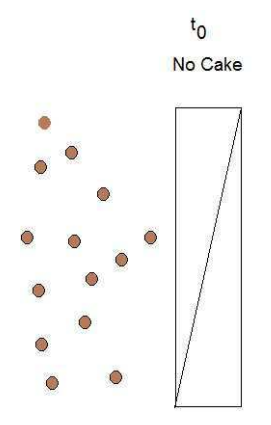

$t^{+}$

Cake Formation
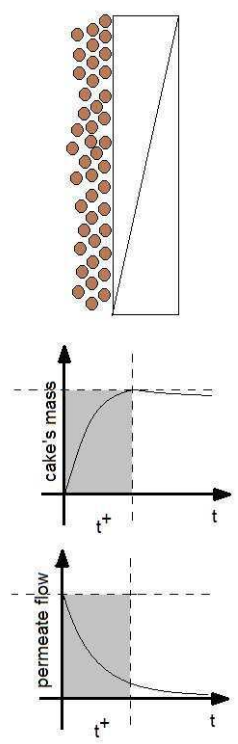

$\mathrm{t}^{++}$

Cake Evolution
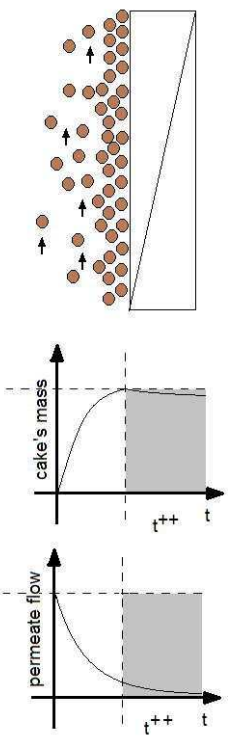

Figure 2: Time evolution of cake mass and effluent flow: at $t_{0}, Q_{\text {out }}=0$; at $t^{+}$, the cake is formed; the time interval up to $t^{++}$shows the further cake evolution 

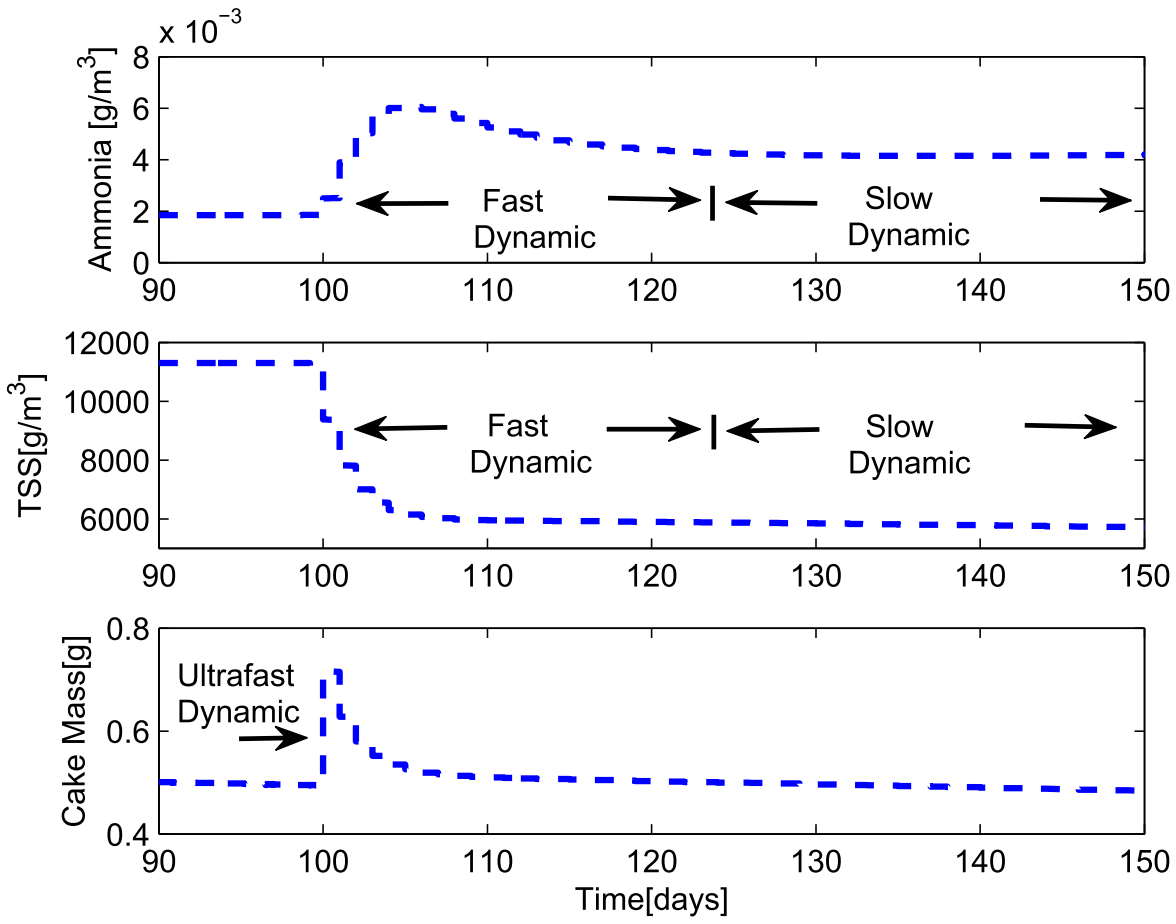

Figure 3: GPS-X simulation. 


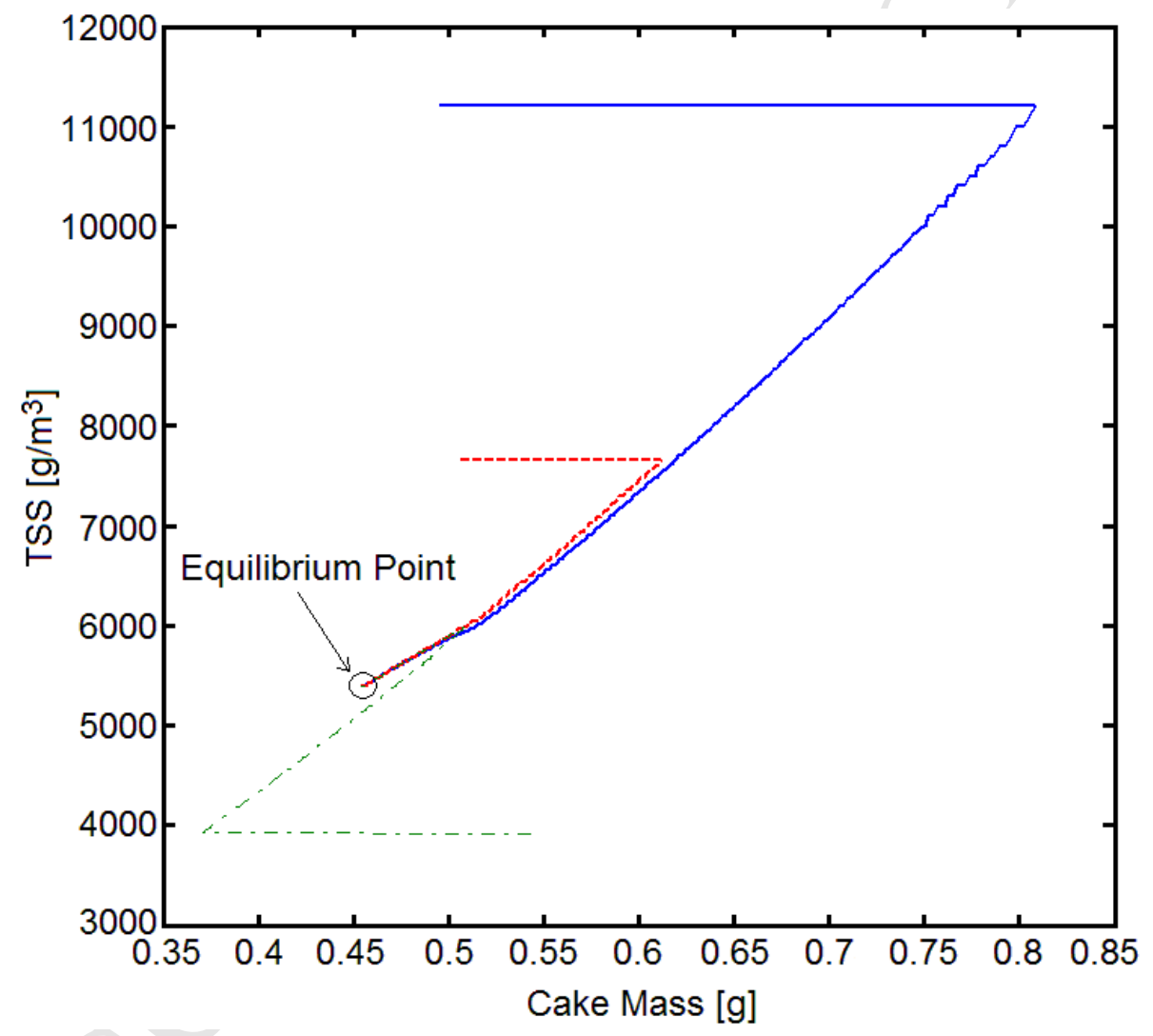

Figure 4: GPS-X simulation: Phase plane plot. Trajectories from three different initial conditions. 


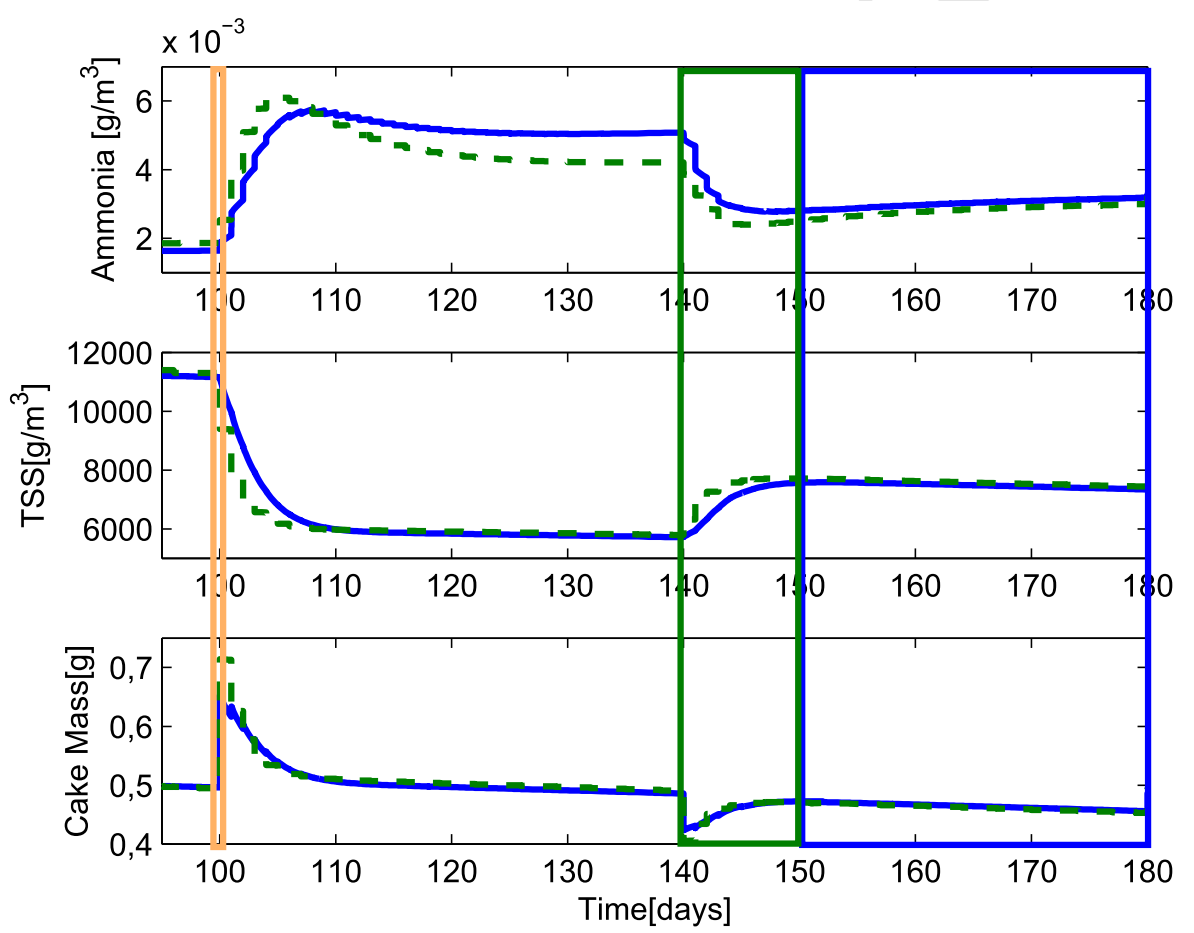

Figure 5: Dotted line: GPS-X with full ASM1 model; solid line: proposed simplified model. Orange window - Ultrafast; Green window - Fast; Blue window - Slow. 

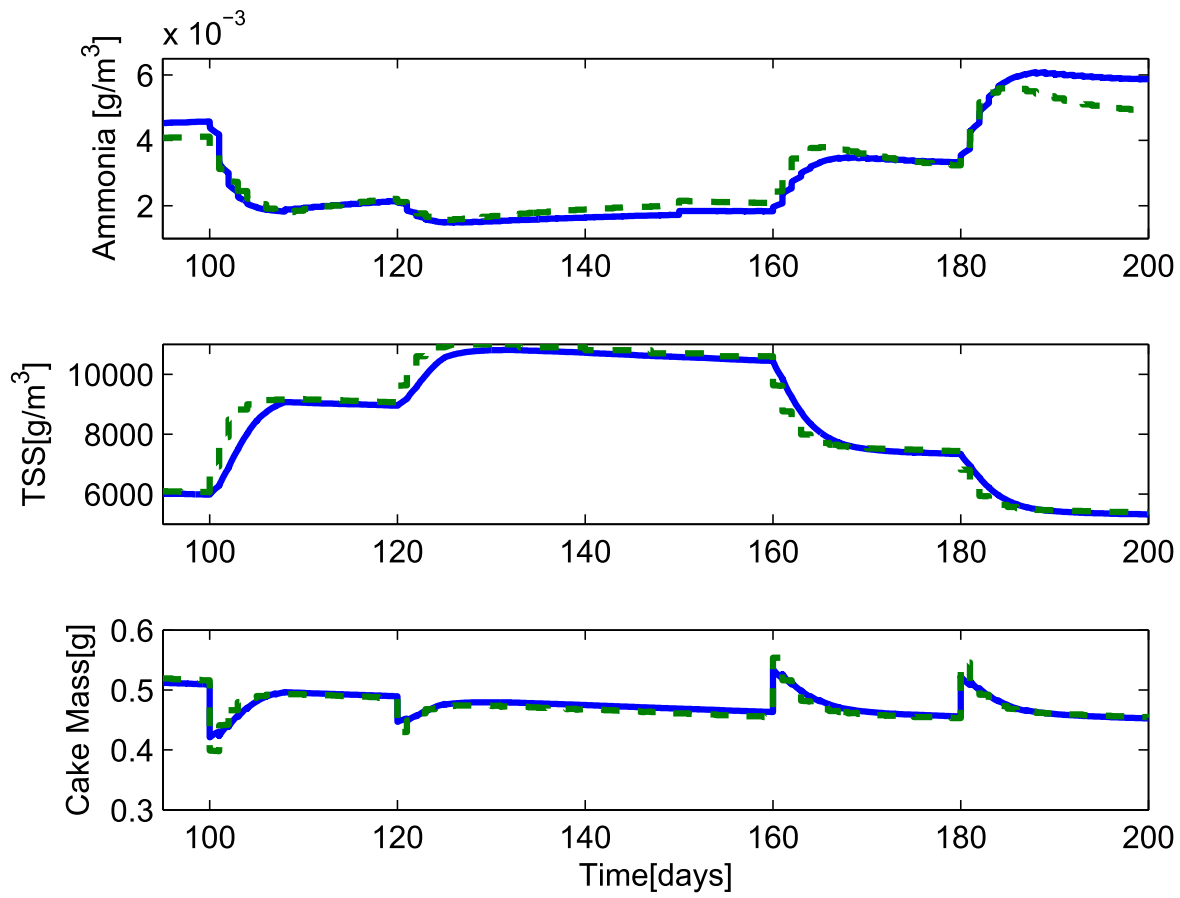

Figure 6: Cross-validation with different initial values and setpoints. Dotted line: GPS-X with full ASM1 model; solid line: proposed simplified model. 

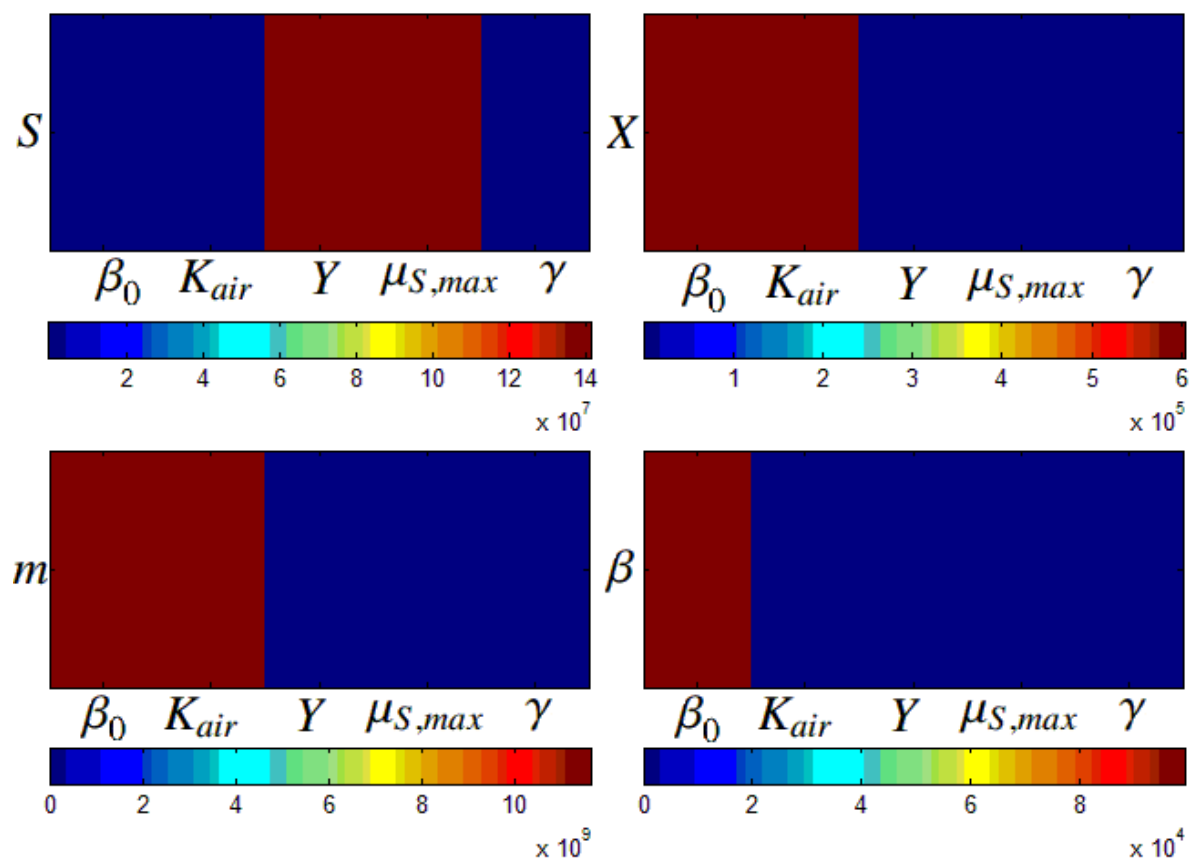

Figure 7: L1-norm of parametric sensitivities 

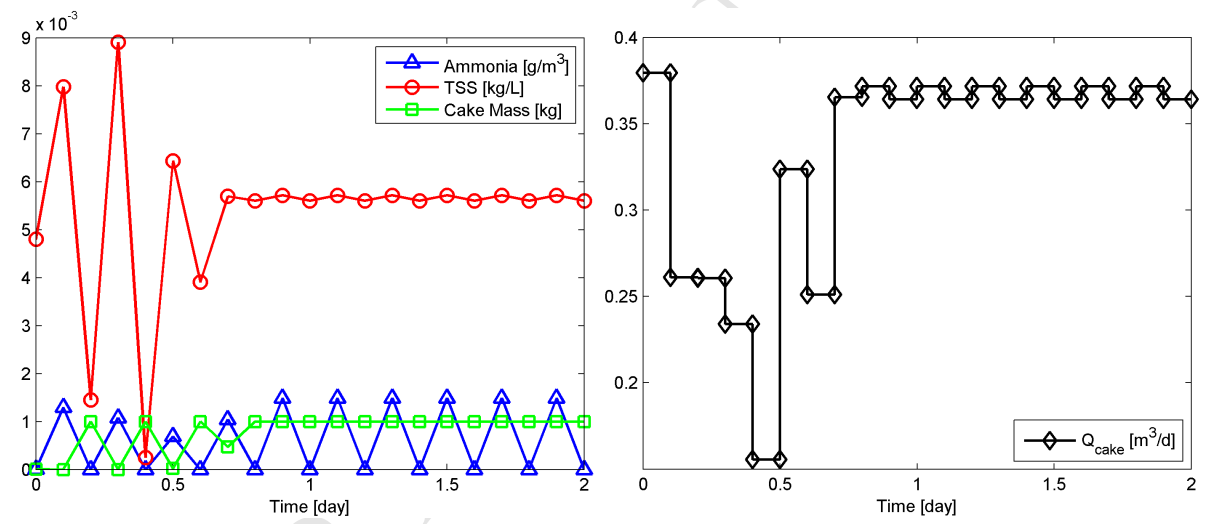

Figure 8: NMPC applied to MBR model: state evolution (left) and control moves (right) 